\title{
"I hope I get movie-star teeth": Doing the exceptional normal in orthodontic practice for young people
}

\author{
Anette Wickström \\ Linköping University Post Print
}

Tweet

N.B.: When citing this work, cite the original article.

Original Publication:

Anette Wickström, "I hope I get movie-star teeth": Doing the exceptional normal in orthodontic practice for young people, 2015, Medical Anthropology Quarterly.

http://dx.doi.org/10.1111/maq.12228

Copyright: American Anthropological Association

http://www.aaanet.org/

Postprint available at: Linköping University Electronic Press

http://urn.kb.se/resolve?urn=urn:nbn:se:liu:diva-119855 
"I hope I get movie-star teeth": Doing the exceptional normal in orthodontic practice for young people

\section{Wickström, Anette}

Abstract

Orthodontics offer young people the chance to improve their bite and adjust their appearances. The most common reasons for orthodontic treatment concern general dentists', parents' or children's dissatisfaction with the esthetics of the bite. My aim is to analyze how esthetic norms are used during three activities preceding possible treatment with fixed appliances. The evaluation indexes signal definitiveness and are the essential grounds for decision-making. In parallel, practitioners and patients refer to self-perceived satisfaction with appearances. Visualizations of divergences and the improved future bite become part of an interactive process that upholds what I conceptualize as 'the exceptional normal.' Insights into this process contribute to a better understanding of how medical practices intended to measure and safeguard children's and young people's health at the same time mobilize patients to look and feel better. The article is based on an ethnographic study at two orthodontic clinics.

\section{Introduction}

Ellen and her mother are sitting side by side on the dentist's chair reading a handout from the orthodontist, who just left the cubicle. Ellen is ten years old and visiting the orthodontic clinic for examination and preparation for braces. I am sitting on a chair in the corner, trying to listen to Ellen without being in the way of the orthodontists and assistants moving between cubicles. Ellen is holding a mirror, and her mother reads the text in a whisper, "Look in the mirror. Where in the mouth do you think the fault or the problem is situated? Mark with one or 
several crosses." Ellen puts many crosses on a picture of the jaws. Her mother goes on reading, "How important is it for you to get treatment for your defective bite? Put a cross on the line." Ellen marks 'it's ok.'

Embedded in clinical biomedicine's endeavors to care and to cure are procedures of setting standards for what is normal, pathological, or divergent. Medical practices involve identifying 'the fault,' 'the problem' or 'the defect,' as in the orthodontic clinic referred to above, and finding solutions to the problems. Medical practitioners do surgery on children to make them look more normal, including non-controversial surgeries such as correcting cleft lips and palates or protruding ears, as well as controversial surgeries such as lengthening the legs of children with achondroplasia, changing the features of children with Down syndrome, or the genitalia of newborn children with atypical sex development (e.g. Parens 2006, Zeiler and Wickström 2009).

The concept of normal biological states was established when knowledge about the human body was being synthesized in the early $19^{\text {th }}$ century (Lock and Nguyen 2010). Biomedicine described characteristics of individual bodies and assessed them against values based on statistical analysis of the population. Bodily variations came to be defined in terms of deviation from a statistical norm. Earlier moral classifications of the human body faded, but their moralizing force remained in medicine's preoccupation with bringing about the normal (Lock and Nguyen 2010). Normal does not necessarily mean the ordinary healthy state, but often what can be improved upon. Canguilhem (1989) argues that a human characteristic is not normal because it is frequent, but frequent because it is normative in a given life context. Thus, the biological classifications and categories used in medical practice are imbued with moral meaning. Medicine, says Mol (2002: 60), sets the standards modern people wish to live up to. It may appear as if biomedicine forces itself upon us and determines what we think of as 
normal. However, norms are not embraced in isolation; medical practitioners, patients, regulatory agencies, and health authorities have to agree on their value (Webster 2002; 451). Medical practice interacts with societal norms and people's identity work.

In this project, I study state-financed orthodontics for young people in order to put a familiar practice under scrutiny. Orthodontics serves as an example of categorization of young people and of practices in which young people's features are evaluated and judged. The aim is to understand the interactive processes at the clinic, when the standards are set in relation to the bite and the teeth, and how young people make meaning of the offer to correct their bite. Categorizing young people and their appearances in order to safeguard their health is a challenge to professionals and officials, in that the categorization processes can augment medical need and reinforce social recognition of the importance of appearance to well-being. A critical examination of a frequently occurring practice can help us understand the technical and social processes taking place in the growing number of medical milieus where function and appearances are intertwined.

In Sweden, more than one in four young people undergo state-financed treatment with fixed appliances. The different actors involved contribute to establishing the norm for teeth and jaws and what is considered to be good occlusal development and a nice smile. On the one hand, orthodontics is charged with setting the standards for children's occlusal development and esthetically evaluating the appearances of the bite. The general dentist informs young people that they have teeth divergences and that an orthodontist should evaluate their need for treatment. An interview study of patients aged 13-19 years showed that most of the interviewees had not previously perceived any problems with their teeth (Trulsson et al. 2002). The decision to undergo orthodontic treatment was actually based on external influences, while the young 
patients considered that they had made independent decisions. On the other hand, the young patients and their parents have ideas about what constitutes a well-functioning and good-looking bite. Orthodontists report that they are receiving increasing pressure from parents and young people who wish to have treatment with fixed appliances, even though they have no valid reasons for receiving state-financed treatment (Boström 2010). Besides the different actors' understandings of norms for the teeth, advertisements intended to recruit patients to competing dental services present norms about the bite. Below is an advertisement from the national dental health service in one Swedish county. The message is to 'make a contract and secure your smile.' When the dental service invites young people to take care of their oral health, it simultaneously presents norms about what one should be ashamed of and how to take measures.

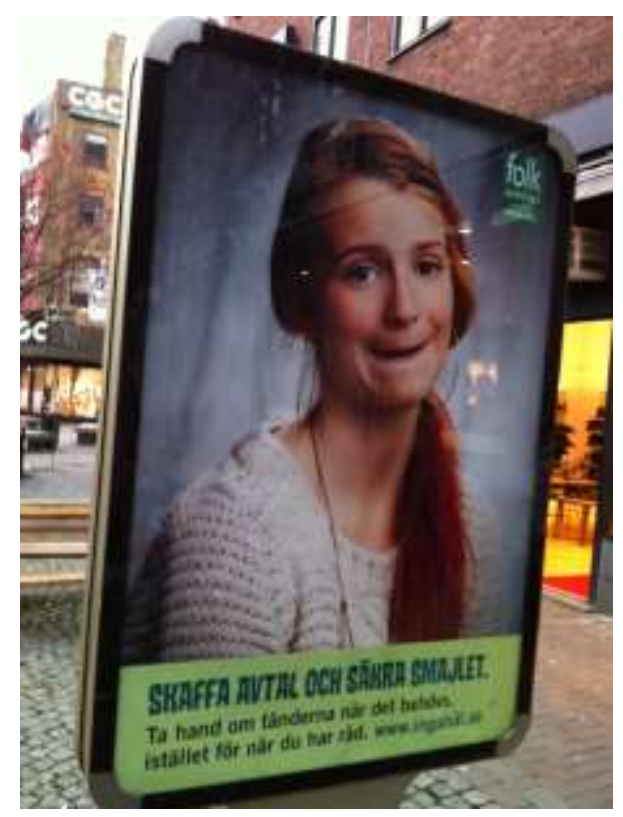

Figure 1. Marketing oral health services.

The landscape of subsidized treatment, orthodontists' commissions, young people's and their parents' wishes, and competitive services comes together at the clinic, in the actual practice of selecting and enrolling young people. Specified norms are used to judge the divergences and choose the individuals who can be eligible for treatment free of cost. 
Ideals about attractive bites and appearances are defined simultaneously. When Ellen fills in the handout together with her mother, as the introductory on-the-spot account from my ethnographic fieldwork shows, she is involved in doing divergences.

Moreover, as the analysis will show, she not only searches for solutions to her stated problems, but makes meaning of the treatment to come and aspires to having excellent teeth. What I argue is that the orthodontic technologies of scrutinizing and improving the teeth and the jaws in line with certain norms trigger ideals that sometimes are exceptional. The technologies may arouse expectations that are outside the scope of orthodontics. Unintentionally, a practice that brings great benefits to many patients acts as a technology of the self. The self is mobilized to desire an improved and sometimes an excellent bite, and to work hard in order for the treatment to be successful (cf. Lock and Nguyen 2010; 293). The point here is not to question orthodontic practices that are commissioned by the state to ensure that children have good occlusal development. Instead, analyzing the confusion of certain norms and exceptional ideals in orthodontics constitutes an effort to understand medical practice and therapeutic subjectivity, to understand how norms are established in practice and how individuals negotiate these norms when they are mobilized for transformations of the self through the use of medical technologies.

The analysis is focused on the following questions: How are the different actors, instruments and practices active in the process of evaluating facial features, setting norms and creating ideals? What do processes of identifying divergences and setting the standards for treatment do to young people, to the norms and the ideals? But first, a few words on orthodontics in Sweden and the theories and methods used.

Orthodontics in Sweden 
In 1974, a state-financed dental insurance system was launched in Sweden to equalize class differences in oral health. However, many dental benefits were eliminated during the economic crisis of the 1990s. As a result poor dental health has once again become a social marker separating social groups. Orthodontics is one of the remaining subsidized treatments. Its goal is to create equal conditions for children and young people to have good occlusal development. In Sweden, an average of 27 percent of young people receives state-financed treatment with fixed or removable appliances. The treatment is subsidized by the state before the age of 20 . If someone whose problem cannot be covered by the subsidy still desires treatment, the private expense is approximately 3,000 Euros. Complications are common, such as decomposition of the roots of the teeth, which happens in 11-28 percent of cases, and some patients' teeth relapse after completion of treatment (SBU 2005). In a review of the sociology of oral health and healthcare, Exley (2009) describes a shifting emphasis in orthodontics from function to appearance. According to the Swedish Council on Health Technology Assessment (SBU 2005), the most common reasons for treatment concern esthetics and life enhancement.

Body norms, ideals, and practices

My analytic approach is influenced by medical anthropology and sociology, and the argument that biomedical technology works as technologies of the self and that people's bodies are transformed in line with local conceptions of the normal and the divergent (cf. Lock and Nguyen 2010; 302). According to Shilling (2003), the body is an unfinished biological and social phenomenon, an entity that is in the process of becoming. This is illustrative of how children are the targets of societal interventions and practices in which their bodies are measured and weighed. The body is a project that may be worked upon, and it constitutes an important part of an individual's self- 
identity. In a society with advanced technical knowledge these processes are more sophisticated and radical (Shilling 2003). The possibilities to correct bodily divergences observed by professionals in social institutions and by the parents or the child are farreaching.

In medical practices esthetics and health are entangled, and esthetics is making inroads into established medical domains. Edmonds (2013) research on obstetrics-gynecology illustrates how medical needs include qualities such as life enhancement and psychosocial benefit. The rising acceptance of aesthetics in medicine reflects that appearance is socially recognized as being important to well-being and an indicator of a healthy state (Edmonds 2013). In orthodontics, the ideal occlusion construct has traditionally been related to facial appearance (Ackerman 2010). However, in contemporary dentistry, the self-perceived level of attractiveness related to the patient's own self-concept is a parameter used when orthodontic services are offered. In this selfconcept/well-ness model, esthetic enhancement of the bite is presented as life improving (Ackerman 2010).

Also important for my analysis is the science studies literature and its claim that in studying practices we can trace the network and understand how bodies are enacted in practice. In her work on atherosclerosis, Mol (2002) concludes that a disease is never isolated from the practices associated with it. Diagnosis is part of what is done in the interaction between material elements, the medical profession, and patients' bodies. Mol (2002) focuses on how activities, events, and instruments are put together in 'doing a disease,' which brings me to my focus on 'doing divergences and normality.' Not only bodies, but also meanings, norms and ideals concerning the body are enacted in practice. 
To understand the internal workings of a practice in which children's bodies are assessed and to see how norms and ideals are constructed within it, I turn to the making of norms and ideals that happens in orthodontic practice. Rooms, chairs, tools, images, $\mathrm{X}$-rays, and indexes are active agents when occlusal divergences are evaluated and treatment recommended. I want to trace the orthodontic network and investigate the technical processes and social aspects of categorizing young people's teeth and jaws. Classifications of people - in this case 'having straight teeth' or 'being in need of orthodontic treatment' - do things to people. Hacking (1999) has paid specific attention to how categories used in scientific examination interact with the people who are categorized. He argues that as soon as people are categorized, they change how they view themselves. Producing new knowledge cannot resolve possible confusion. Instead, it is important to study what knowledge about people does to people (Hacking 1999). The meanings of divergences and treatment needs, norms and ideals may change during the process, as a result of the images of their bites and teeth young people are presented with. In this project, I investigate the interactive process or the two-way influence at the orthodontic clinic, that is, what the knowledge produced does to the norms and to young people, and in turn, what young people's experiences do to the orthodontic norms regarding teeth.

In the banana landscape - strategically situated ethnography

The orthodontic clinics I visited are landscaped like banana stems, and patients are examined and treated in eight cubicles. The cubicles are separated only by screens, and orthodontists and their assistants work closely together. The community of orthodontic practice seems well coordinated, resulting in a concordant view of the goals of treatment. Compared to a hospital and its multiple enactments of, for example, atherosclerosis (Mol 2002), orthodontic clinics are smaller units where resistance to 'the 
ordering' is more easily overcome and the different parts are well united. Staff members emphasize that they try to maintain a unanimous view of the work they do.

The present article is based on an ethnographic study of three activities preceding possible treatment with fixed appliances: consultation, examination, and information. ${ }^{\mathrm{i}}$ This multistage process, common in countries where the cost is wholly or partially covered by public funds, makes up the grounds on which the divergences of young people's bites are valued and a transformation of the bite is planned. To begin with, I attended and took field notes on 83 consultations (33 were audiotaped) in which patients were sorted according to divergences and treatment needs; 40 were enrolled at the clinic, decisions for 21 patients were postponed, 8 girls and 3 boys were told that their divergences were not severe enough to warrant free treatment, 3 boys and 2 girls were asked to improve their oral hygiene before treatment could be considered, 3 cases concerned other complex of problems, and finally, 2 girls and 1 boy were doubtful about having treatment.

In collaboration with the orthodontists, I asked eight patients who were enrolled at the clinic to participate in my study - four girls and four boys with different degrees of divergences. First, I observed and video-recorded four examinations to get a sense of how the material representations that constitute the foundation for the orthodontist's planning are produced. Second, I joined the eight patients and their parents when they visited the orthodontist and received information on the plans for their corrections. I also interviewed the patients, some of them together with their parents, and had informal conversations with the staff when they prepared for the patients' visits, and during coffee breaks and lunches. Finally, I interviewed a girl who declined treatment that the general dentist and the orthodontist had recommended. 
Before meeting the first patient, the orthodontist warned me that I might not get consent to videotape the examination because it is bodily intrusive. However, the young patients allowed me to join them, and six of eight allowed me to videotape the examination and the information session. The other two consented to my audiotaping. All of them seemed to enjoy being interviewed. As one ten-year-old girl said, "This was really fun." However, the principle of ethical symmetry broadens the issue of ethics, depicting it as 'part of the ongoing, everyday process of the research' (Christensen and Prout 2002: 493). In this study, I not only negotiated access and permission on one occasion, but always tried to give the participants a choice. The patients have been given pseudonyms while the orthodontists are called orthodontists. In the field, the orthodontists were invaluable guides and shared their personal knowledge and experiences with me. However, my analysis of what is done in practice is not a scrutiny of any single practitioner, but of the official wheel of orthodontics. My focus is on the interactive processes and the material, practical, spatial, and technical processes involved.

\section{Coding divergences}

On a rainy day in 2012, I joined an orthodontist who was traveling to a small village to consult with 33 patients in the district. The consulting room was crowded, and more so with me on a chair in the corner. Each patient together with a parent, and perhaps a sibling, the general dentist, and sometimes his or her dental nurse, saw the orthodontist and the orthodontic nurse for about ten minutes. The young patients seemed to be varyingly motivated. Some seemed to accept someone else's decision about the need for treatment. As 12-year-old John stated, "You don't want to have braces. It's a little hard." Others saw it as a matter of course or even a winning ticket. Sara declared, "I always heard that I have very nice teeth but that they're crowded and that my bite is crooked, I've always known I wanted braces.” And Amanda, 12, said, “One has to go 
through a lot for one's appearance." She was very eager to start treatment, although her mother was of the opinion that she was fine just as she was. In this chapter I will show how divergences are coded during consultation.

Judgments are based on an evaluation of the morphological deviation, i.e. the deviation from an accepted norm, and on an esthetic evaluation of the appearances of the teeth. One orthodontist explained, "The upper and lower jaws are supposed to fit together, without uneven clenched teeth. Undeveloped teeth should not be allowed to push on already developed ones." The harmony strived for also concerns the face, and orthodontists are trained to pay attention to lopsidedness and other features. The perceptual structures in orthodontics are easily identified in the word itself - 'ortho' meaning straight or correct and 'dont' meaning teeth - as well as in the evaluation indexes. In Sweden, four different indexes are used that allow the orthodontist to code the need for treatment. These include ICON, the Index of Complexity, Outcome and Need (Daniels and Richmond 2000), where overbite, cross-bite, etc., are measured in millimeters and given a weight in a total sum of divergence. However, the Swedish Council on Health Technology Assessment reports that there is a lack of scientific data for determining whether the indexes measure what they are supposed to measure (SBU 2005). In the 1970s, two independent orthodontic expert conferences stated that a useful definition of malocclusion did not exist (Moorrees et al. 1971, Isaacson et al. 1975). An orthodontist cannot predict whether or not a malocclusion will lead to some sort of handicap. Only the patient's possible symptoms can say something about the problem (National Research Council 1976). Ackerman and his colleagues state that the definitions of 'ideal occlusion' are still vague and imprecise (Ackerman, Ackerman and Kean 2007). However, the indexes are inscription practices that signal definitiveness. 
They are the essential grounds for decisions in a practice where the bite and appearances are standardized and made into scientific objects.

The orthodontists, nonetheless, find it easy to judge the so-called objective need through consulting the indexes. Moreover, a study of the ICON used by an expert panel indicates very high agreement on the decisions (Firestone et al. 2002). In 2012 when I was doing fieldwork all patients whose scores were in the upper half of mild divergences could be enrolled. Comparatively, that was a generous distribution. Other counties were stricter due to their financial resources or in order to cut down the queues (oral presentations at the Annual Dental Congress, Stockholm, November 18, 2011). So, even if the norms are the same when measured by the index, the dividing line for getting state-financed treatment or not may differ over the years and between the Swedish counties.

Being enrolled means a possibility for a young person to transform the bite and the appearance, but also accepting that one has to make sacrifices. The following case shows the proportions of the work involved for an individual taking on treatment. Moreover, it shows how the esthetical aspect is inevitable in the interaction at the clinic. Seventeen-year-old Sara and her father listen to the orthodontist:

Orthodontist: if there was only a little space in the upper jaw and totally straight in the lower jaw it wouldn't have been enough for free treatment, but actually, since there is very little space down here you get it for free, if you keep it like this, not much will happen to your bite during your adult life $[\ldots]$

Father: it's not good as it is

Orthodontist: well actually I think she's rather pretty just as she is 
Father: yes (Sara gives a laugh)

Orthodontist: but certainly it will be nicer.

Sara has moderate divergences with an increased overbite and crowded teeth. She is eager to start the active treatment period that will take up to four years. It involves placing elastic rings between her posterior teeth to create space for two orthodontic bands, extracting four teeth, fixing of a transpalatal wire in the palate, and having an active fixed appliance for two years. Then the gums will be adjusted to prevent relapses; some fibers will be cut off around previously rotated front teeth. A removable plastic retainer in the upper jaw will be worn nights for one year, and the second year every other night. Post-treatment involves keeping the wire at the backside of the front teeth in the lower jaw until she is 25 and in the upper jaw for longer.

What we understand from the excerpt is that Sara could keep the bite as it is without problems. But she is prepared to put lots of work into getting a nicer smile, and her father supports her ambitions. Even if the orthodontist tries to avoid giving Sara the feeling there is something wrong with her appearance, the practice in itself constitutes an incentive to desire a nicer bite and to conform to normative expectations about the bite.

Frida, the interviewee who rejected having treatment, got the same message at the clinic, but in contrast to Sara she found it strange to be offered treatment for her looks:

He said that it was mere esthetics; I wouldn't have any problems with my teeth if I didn't have braces, but I could get them straighter. [...] I asked why it was necessary to be totally straight in the mouth and then he said that of course it is nice as it is but you can always become prettier, and then I thought it was an odd thing because if it had been another part of the body and I went to the doctor and I 
spoke about my nose or my ears, then it would have been very odd to say 'we wish to operate on your nose because it is crooked.' It would have been a very insulting situation.

The process of identifying and selecting patients means setting the orthodontic norms. Divergences are singled out and esthetic aspects are manifested in the communication with the patient or, alternatively, the offer of treatment concerns mere esthetics. When Frida understood that she was being offered mere esthetic changes in her bite she told her mother, "I would rather fix my lips." A medical authority had the legitimacy to offer her esthetic changes, and her answer may be understood as a rhetorical question; "why not another part of my body?" Frida rejected treatment, but for almost all the young people coming for consultation the coded divergences became a possibility for personal improvement. One dentist told me, "The patients' demands have increased if we look back 20 to 25 years." However, he went on: "We do more when we can do more." Patients' demands and advanced technical knowledge in orthodontics interact and reinforce each other. The enrolled patients invest considerable effort for many years in getting a better and better-looking bite. In the following I will examine how aspects of appearances and function intermingle during the process of measuring and judging young people's bites.

Medical need or self-satisfaction with appearances

During consultation, the orthodontist asks about the patient's views on his or her bite prior to the examination. When the orthodontist enters the room, Ellen, whom I mentioned in the introduction, is told to sit up on the edge of the dentist's chair. In that way, the orthodontist can discuss Ellen's bite and understand her view and experiences. When asked, Ellen states that she chews well and that she doesn't have aching jaws or 
headaches. The orthodontist explains: "sometimes when people have a bite like yours, where you slip a bit, they may have headaches, but not all of them have." The reference to headaches is common among patients, parents, and orthodontists, in contrast to the experts' claim about the difficulties of predicting the consequences of a malocclusion (Ackerman, Ackerman and Kean 2007). The argument 'to avoid headaches in the future' seems like a way to legitimate orthodontic practice. In cosmetic medicine legitimation work has shown to relate to the health policies (Gimlin 2007). A statefinanced system, like the Swedish system of which orthodontics is a part, produces references to medical need, according to Gimlin (2007). Ellen is aware that something is wrong with her bite. Her mother tells me that Ellen has been reminded by the general dentist every year since she was five that she needs dental corrections. The divergences, however, do not cause her any physical problems.

After the conversation the orthodontist asks Ellen to lie down. As soon as she does so, the estimation of divergences depends on the orthodontist's instruments and view. A slide caliper is used to measure gaps, a ruler to measure overbite and the eyes to see if the nose is in line with the space between the front teeth. The instruments point at gaps, crowding or a broken centerline, and highlight asymmetry. The transition from sitting face-to face to the patient lying down on the dentist's chair implies a change in focus from the patient's experiences to the orthodontist's instruments. The playing down of the patient's point of view is reinforced by the fact that the mouth is filled with the instruments. The orthodontist has the indexes in mind and the bite is translated to a fixed number. In contrast to Sara's, Ellen's divergences are considered very difficult. In such cases, the orthodontist is not thinking at all in terms of a number. The primary ambition is to motivate the patient and the parent to accept the treatment. 
Other patients referred to symptoms such as pain, teeth-grinding or to something they found ugly in their bite. When the patient had too small divergences to qualify for statefinanced treatment, the orthodontist tried to convince the patient that the treatment risks and the hardships involved were greater than the possible gains. Nevertheless, the reference to self-perceived satisfaction with appearances was still available, especially in the information about the possibility of self-financing.

The orthodontic offer of self-improvement relates to a broader spectra of practices focused on enhancing individuals' capacity to manage themselves. Accounts of cosmetic surgery provided by British women, characterize operation as a response to exclusion, inability or being marked as different from others (Gimlin 2007). The women conceptualized their needs medically and their 'problems' were legitimated by medical professionals. Similarly, an improved bite is thought to make you feel better and also enhance your social and economic possibilities. In a cultural setting where healthcare is publicly funded, not only medical need but also the risk for social exclusion is referred to for legitimating cosmetic surgery (Gimlin 2007). The fact that orthodontics in Sweden is state-financed may feed arguments of life enhancement and psychosocial benefit. The treatment is considered an offer to do your best and to safeguard this specific aspect of the self. The enrolled patients and their parents emphasize the advantages and their gratitude.

Young people may experience shame and desire changes in their dentofacial traits. The orthodontists sort them by transforming divergences into figures and indexes. Experiences of esthetic divergences intermingle with measurable standardized divergences, and different kinds of normalities appear. Both the orthodontists and the young patients refer to normality in the sense of 'not needing to be ashamed but being satisfied with one's appearances.' However, in the public function of orthodontics, 
normality more often refers to having 'a good stable bite,' and shame is outside the mission and thus dealt with summarily. The shift from the patient's experiences to calculations resulting in indexes constitutes a transition from a living figure and experiences of shame to more distinct and comparable figures of divergences. The indexes make the sorting out possible.

The legitimation work in orthodontics includes efforts to play down the esthetic aspects and the processes of judging. One dentist told me that the word 'normal' is no longer used in orthodontic practice; the terms 'divergences' and 'treatment need' are used instead. It seems that the team tried to stop labeling what was normal, to neutralize the negative meanings associated with improving appearances. Rather than explicitly labeling 'the normal,' that very practice of labeling was somewhat hidden behind references to medical need and psychosocial benefit. However, when divergences are brought together with treatment need they become the foundation for aspirational norms, both medically and socially. In the following I will show how the material representations produced during examination arouse the desire for normalcy in the sense of an ideal.

Visualizing divergences and desiring an ideal

Ellen has just had a wide plastic spoon with plaster placed in her mouth. The orthodontic assistant is sitting behind her holding the spoon pressed against Ellen's palate, waiting for it to congeal. Ellen starts coughing, waves her arms and says "ah, ah." Her mother gets up from the chair and puts a comforting hand on Ellen's legs, which Ellen moves restlessly. She flinches and is nauseated.

In contrast to the quick consultation, the second procedure in preparing for treatment, the examination, is time-consuming and uncomfortable. An assistant is in charge of 
producing a series of material representations of the jaws and the bite, which takes approximately fifty minutes. First, a large number of digital pictures are taken of the face and of the mouth from the outside and inside, with the help of a mirror and a wide plastic spoon that keeps the lips apart. Then plaster casts of the jaws and three different types of X-ray pictures are produced. The material representations are visualizations of the divergences and are used when the orthodontist makes plans for treatment, as pedagogical tools when discussing the treatment with the patient and a parent, but also as documentation.

During the examination, the patient is asked to make her own representation of divergences, to mark the problems on a picture of a face where the row of teeth is visible (see the episode with Ellen and her mother, referred to in the introduction). All these procedures reinforce what Ellen and her mother have understood ever since the general dentist first told them about the problem. Writing practices, such as Ellen's marking of problems and motivation, organize distributed cognition and coordinate action at the orthodontic clinic. The material representations, including Ellen's own, provide the material and cognitive infrastructure for the orthodontic network. When the divergences are visualized in more durable materials, they work as an ordering strategy and have interactional effects.

The different actors in the network are centered on the artifacts and start to move in the same direction - toward an improved bite. The material representations order the thinking on normality because they represent divergences. Interestingly, Ellen marks many 'problem' spots in her face, but still gives a low rating for motivation (see page 1). She does not wish to go through the treatment, but she prefers it to living with the divergences that have been discussed with her for so long, highlighted during the consultation and visualized during the examination. She also wishes she could avoid 
feeling ashamed, as she told me during the interview, "Sometimes I'm ashamed of my teeth like in the class picture." Ellen has been hiding her teeth and is longing for a nicer bite: "I hope I'll get sort of movie-star teeth like Miley Cyrus and Taylor Swift." Ellen's hope for the future is for something 'exceptional,' something she recognizes as features of some movie-stars. The quest for the exceptional becomes possible when orthodontics set the standards for appearances and individuals find meaning in enhancing theirs.

Coordination and preparation for improving the bite

One month after the examination, Ellen, her mother and the orthodontist are crowded in front of the computer screen looking at all the digital representations of Ellen's bite. The orthodontist talks about being accustomed to visualizations of the bite, "Then we have some pictures from the inside of your mouth, and this is a little strange for you and your mother to look at because you usually don't look at your teeth so close up, but I look at teeth like this all the time, so I don't think it looks strange at all." The comment is meant to normalize looking at pictures like this. At the same time it lays the foundation for the rest of the information session and the orthodontist's pointing out of what is relevant to notice and, ultimately, to treat. Scrutinizing the visual representations and learning to see and judge esthetics means coordinating action for improving the bite.

The information session lasts for about 50 minutes. The plaster casts, or 3-D digital versions, are used when the orthodontist demonstrates the divergences or the possible changes of the bite. When the divergences are discussed around material representations instead of around the body, the participants do not talk about what the patient feels in his or her jaws or head, but the focus is on the screen and the artifacts. Sometimes the patient seems engaged during the information session and asks questions, but mostly the session involves one-way communication. The orthodontists signal in different ways 
their professional vision and their skills in interpreting the representations. Bit by bit, and under the orthodontist's leadership, the participants' thoughts are assembled, which will make the transformation of the bite and the face a reality.

The professional vision communicated during the information session concerns norms, divergences and possibilities to correct the bite. When Michael, a 15-year-old boy, and his mother are sitting in front of the computer, the orthodontist signals the norms for a perfect bite; the lips should 'cover the front teeth,' a person should 'show teeth when smiling,' and the jaws should work 'like a zipper' to ensure 'optimal contact between the teeth.' The statements move between function and appearance, and it is difficult to distinguish between the two. The orthodontist confirms what Michael has already learned, "your front teeth lean outwards," "your upper jaw is a bit in front of your lower jaw" and "your upper jaw should actually be over there." The activities entail a move from the present toward the future. The orthodontist shows a representation of the future bite. Analysis software has been applied to a profile $\mathrm{x}$-ray of the cranium to calculate how to move the teeth and the jaws. The aim is to "pull them in a little bit," "move these teeth a bit down and backwards," "make your upper and lower jaw even" and "close gaps." The professional language establishes the orthodontic norms and the scientific effort to overcome the flaws of the present bite.

An orthodontist may work hard to motivate a patient and the family to take on a long and complicated treatment, as exemplified in the information session with Ellen and her mother. In the beginning, the orthodontist comments on the pictures using words like "your teeth are all over the place." The orthodontist then makes a hand gesture I have seen many times. The hands act as the jaws and the fingers as the teeth. The upper jaw (the fingers of the right hand) goes down behind the lower jaw (the fingers of the left hand). Then, in a distinct movement, the orthodontist lifts up the right hand and moves 
it in front of the left hand, symbolizing the planned change from a protruding jaw to a corrected bite. "Wouldn't be bad at all," the orthodontist comments. The material representations, the orthodontist's words and gestures work together and mutually amplify each other.

Finally, the information session comprises one more writing practice, namely the treatment agreement. The paper contains information on the offer of treatment free of cost, the routines at the clinic, what is expected of the patient, risk factors (in fine print) and last but not least, the treatment plan. The paper is to be signed by the patient and a parent if they accept the plan. This is the first step in delegating a great deal of the activities to the family. ${ }^{\text {ii }}$ Ellen's is a complicated case, and the treatment may take most of her adolescence, though the orthodontist states: "We don't have braces every year when you're growing up, but we must have breaks."

To sum up, the information session involves a reinforced establishment of the divergences as well as the solutions to them. The bite as it is now is presented as a problem. The corrections are presented as the solution and the future bite as a better one. The information provided creates the norm and sparks the desire for a better bite. In the final part I will discuss how the exceptional normal is expressed and brought about in practice.

Doing "the exceptional normal"

On a cold winter day, 17-year old Sara and I find a room just inside the staff dining room. She has just started the long road to correcting her moderate divergences by removing four teeth. During the interview, I understand that she has been having a difficult time, with a great deal of pain and inability to chew for two weeks. But she assures me she does not have problems with her weight because she and the family have 
planned well and bought liquid nutrition of different kinds so that she can carry on with her schoolwork. Sara explains about her commitment.

Sara: it will take until I'm 25,27 . It will be fine in the end so I am grateful to get this

Researcher: is there anything else you can compare it with

Sara: (thinks for a while) yes... it's like school, it's hard now, but it will be fine in the end.

In the end, Sara believes, she will benefit from struggling with school, as well as with the fixed appliances. A dental engineer at the clinic also uses school as a metaphor for taking responsibility and improving one's possibilities. 'I feel sorry for kids who don’t get support to do well at school," he said, "and it's the same with orthodontics." Investing in the body and appearances is compared to improving future prospects. The patient is striving to prepare for the future and to get better opportunities, which are thought to increase with a better-looking bite.

Earlier research shows that girls emphasize appearances more than boys when discussing the influence of the malocclusion. Boys tend to focus more on functional aspects (Trulsson et al. 2002). Moreover, malocclusion is said to be more worrisome to girls than to boys (Jung 2010). Some of the differences, I would argue, concern different ways of expressing oneself in relation to esthetics. During the information session the orthodontist communicates his perception of Michael's bite, and Michael and his mother learn how to see and judge. Afterwards when I ask Michael why he is at the orthodontic clinic, he says that he would like to have straight teeth and not such an overbite. When I ask why it is important to have straight teeth, he says, "I don’t know, the dentist wanted it, maybe it will be easier to eat, I don't know, I haven't tried having 
straight teeth." I conclude that he is more interested in function than appearances, but he objects, "That's no problem if the bite becomes better looking." Michael speaks about functional improvement but in the end recognizes his interest in becoming better looking. More boys than before seem to be interested in orthodontic treatment with reference to the amount of appeal cases against decisions to the dental care board in the county I studied. ${ }^{\mathrm{iii}}$ Between 2000 and 2010 the girls' appeals were five times as many as boys. In 2012 the figure on appeal cases was six of each gender. The incentives to correct the teeth and create a better-looking bite work on both boys and girls. Wanting to become better looking, as Michael does, becomes possible and can be articulated in a practice in which divergences are marked and treatment offered.

The morphological norms used to select those who are eligible for treatment are strict. These norms, however, are objectives that reach beyond ordinary bites. They do not mirror a common bite, but specify 'the normal bite' as it is defined in orthodontics. This is an ideal that privileges symmetry, regular centerline, and rows of teeth without gaps or crowding. In contrast to a statistical norm that speaks of frequency, the aspirational norm speaks of excellence (Kittay 2006). Here the orthodontist explains to Michael and his father:

What we will strive for is that you will have a bite that brings you closer to this bite at least (shows the x-ray of the cranium with the analysis). This is a sort of ideal bite, which is actually not a normal case one could say, because most people do not have such an exact exact bite, but we strive in this direction.

The ideal referred to mirrors Ellen's dreams of having movie-star teeth; something to strive for, something unachievable but worth trying to approximate. 
To be a committed patient, it is important to consider braces as a chance of thriving and commitment. Here the orthodontist speaks to 17-year-old Emma and her father:

Is this necessary, no, you could keep it like this, it's not a big catastrophe at all, so if you do this it's because it will make you happy, not to make me happy, even if I think it's fun to do this you know. So you should be determined about it yourself because it's rather hard work. Two and a half years with fixed appliances is a rather long period.

Orthodontics is represented as a therapy for achieving a better-looking and better bite in order to be happy. Kittay (2006) argues that the desire for 'the normal' is powerful, and in order to avoid what is considered abnormal, people have to pay a high price. Frida, who rejected treatment, had her doubts about her decision, “Today I think more about it. Will I regret it in the future? Perhaps you wish to have these teeth after all even if you have declined them." When Frida abstains she does not only go against the specialists and most of the patients coming for consultation, but she declines investing in herself, something she believes she may come to regret. The moral dimension of handling the body creates, according to Fox (2012), “a hierarchy between those who choose safe ways to manage their bodies and those who do not."

\section{Conclusion}

The concept of normal always includes the concept of 'desirable.' If that which is frequent is understood as indicating how things should be, then descriptions of that which is common include prescriptive elements (Kittay 2006). Normality, argues Kittay (2006), is bound to norms and thus, basically, a social concept. The bite aimed at in orthodontics does not approximate the average, it concerns norms created in an interactive process between authorities, practitioners, technology, patients and parents. 
The multistage process means involving the patient and the parents in the procedures. The orthodontists and their assistants spend a great deal of time motivating and supporting children and young people so they can manage a prolonged and sometimes painful treatment in spite of their fears or concerns. The young patients, on their part, get access to advanced technology and get orthodontic treatment whether they can afford it or not. At the same time, the well-coordinated community of orthodontics is involved in sorting children and young people and labeling what is divergent as well as desirable concerning the bite. My ambition is not to question the patient-centered method or to reduce the value of children's and young people's experiences of benefitting from state-financed orthodontic treatment. Instead I have raised more subtle questions concerning the interactive process of doing norms in medical practices that aim to improve functional and esthetic aspects of children's and young people's bodies. Insights into this process contribute to a better understanding of how medical practices intended to measure and safeguard children's and young people's health involve unexpected effects.

Different concepts of normality are confused and the orthodontists refer to either 'ideal occlusion' or 'psychosocial benefit.' These are two constructs used in selling orthodontic need, according to Ackerman (2010): the oral health model of the $20^{\text {th }}$ century and the wellness model of the $21^{\text {st }}$ century. In the practice, however, the two constructs are simultaneously in action. Young people are given the chance to improve their bite, and simultaneously to look and feel better and consequently enhance their future possibilities. Orthodontists have the obligation to notice and prevent future problems with the bite. The focus on the future is a third construct at play. It adds, to the wellness model, the risk of feeling bad about the appearance of the teeth in the future, and young people are invited to safeguard this aspect early in life. 
The orthodontic network, including advertising and clinical procedures, constitutes a major incentive for young people to desire an improved bite and to put a great deal of work into achieving it. The perfect bite becomes what patients and orthodontists often aspire to, and it constitutes an ideal. The different actors in the orthodontic network reinforce and uphold what I conceptualize as 'the exceptional normal.' The concept illustrates the ideal image enacted in practice when young people are mobilized to work on the self. The actors' ambitions strive toward perfection, especially when patients are enrolled for mere or mainly esthetic reasons. In the long run, the exceptional normal bite becomes frequent and comes to be regarded as a normal-looking trait. The ideal and the interactive processes have in fact changed the orthodontic norm. Transcending the most representative and focusing on the desirable create a focus on individual responsibility for being healthy and looking good, not only here and now, but also in the future.

\section{References}

Ackerman, Marc Bernard

2010 Selling Orthodontic Need: Innocent Business Decision or

Guilty Pleasure? Journal of Medical Ethics 36:275-278.

Ackerman, James L., Marc B. Ackerman and Martin R. Kean

2007 A Philadelphia Fable: How Ideal Occlusion Became the Philosopher's Stone of Orthodontics. Angle Orthodontist 77(1):192-194.

Boström, Charlotte

2010 Tandställningen Har Blivit Trendig [Braces Have Become Trendy]. Östgöta Correspondenten 25 augusti 2010. 
Canguilhem, Georges

1989[1966 Fr] The Normal and the Pathological. New York: Zone Books.

Christensen, Pia and Alan Prout

2002 Working with Ethical Symmetry in Social Research with Children. Childhood 9(4): 477-497.

Daniels, Charles and Stephen Richmond

2000 The Development of the Index of Complexity, Outcome and Need (ICON).

Journal of Orthodontics 27(2):149-62.

Edmonds, Alexander

Can Medicine Be Aesthetic? Disentangling Beauty and Health in Elective Surgeries. Medical Anthropology Quarterly 27(2):233-252.

Exley, Catherine

2009 Bridging a Gap: the (Lack of a) Sociology of Oral Health and Healthcare.

Sociology of Health \& Illness 31(7):1093-1108.

Firestone, Allen R., F. Michael Beck, Frank M. Beglin and Katherine W. L. Vig

2002 Validity of the Index of Complexity, Outcome, and Need (ICON) in

Determining Orthodontic Treatment Need. Angle Orthodontist 72(1):15-20.

Fox, Nick J.

2012 The Body. Cambridge: Polity Press.

Gimlin, Debra 
2007 Accounting for Cosmetic Surgery in the USA and Great Britain: A Crosscultural Analysis of Women's Narratives. Body \& Society 13(1):41-60.

Hacking, Ian

1999 The social construction of what? Cambridge, MA: Harvard University Press.

Isaacson, Robert J., Richard L. Christiansen, Carla A. Evans and Richard A. Riedel

1975 Research on Variation in Dental Occlusion. A "State of the Art" Workshop

Conducted by the Craniofacial Anomalies Program, the National Institute of Dental Research. American Journal of Orthodontics 68:241-55.

Jung, Min-Ho

2010 Evaluation of the Effects of Malocclusion and Orthodontic Treatment on Selfesteem in an Adolescent Population. American Journal of Orthodontics and Dentofacial Orthopedics 138(2): 160-166.

Kittay, Eva Feder

2006 Thoughts on the desire for normality. In Surgically Shaping Children, Technology, Ethics, and the Pursuit of Normality. Erik Parens, ed. Pp. 90-110. Baltimore: The John Hopkins University Press.

Lock, Margaret and Vinh-Kim Nguyen

2010 An Anthropology of Biomedicine. Chichester: Wiley-Blackwell.

Mol, Annemarie

2002 The Body Multiple: Ontology in Medical Practice. Durham: Duke University Press. 
Moorrees, C.F., C.J. Burstone, R. L Christiansen, E.H. Hixon and S. Weinstein

1971 Research Related to Malocclusion. A "State-of-the-Art” Workshop Conducted by the Oral-Facial Growth and Development Program, the National Institute of Dental Research. American Journal of Orthodontics 59:1-18.

National Research Council

1976 Committee on Handicapping Orthodontic Conditions. Seriously Handicapping Orthodontic Conditions. Washington: National Academy of Sciences.

Parens, Erik, ed.

2006 Surgically Shaping Children; Technology, Ethics, and the Pursuit of Normality. Baltimore: The John Hopkins University Press.

Shilling, Chris

2003 The Body and Social Theory. London: SAGE/TCS.

SBU, Swedish Council on Health Technology Assessment

2005 Bettavvikelser och Tandreglering i ett Hälsoperspektiv [Bite Abnormalities and Orthodontic Treatment from a Health Perspective]. SBU-rapport.

Trulsson, Ulrika, M. Strandmark, Bengt Mohlin and U. Berggren

2002 A Qualitative Study of Adolescents’ Decisions to Undergo Orthodontic Treatment with Fixed Appliance. Journal of Orthodontics 29(3):197-204.

Webster, Andrew

2002 Innovative Health Technologies and the Social: Redefining Health, Medicine and the Body. Current Sociology 50(3):443-457. 


\section{Zeiler, Kristin and Anette Wickström}

2009 Why Do 'We' Perform Surgery on Newborn Intersexual Children? The

Phenomenology of the Parental Experience of Getting a Child with Unclear Sex.

Feminist Theory 10(3):359-377.

Acknowledgments

I would like to express my sincere appreciation to everybody at the Centre for

Orthodontics in Östergötland who supported this research. Special thanks to the orthodontists and assistants who shared their time and thoughts with me during fieldwork. I am very grateful to the participating young patients and their parents who let me join them at the clinics and for sharing their thoughts and feelings. I also thank the anonymous reviewers for their many valuable comments.

This article reports on research funded by the Swedish Research Council (Reg. No. 4352011-1220).

\footnotetext{
i The procedures have been approved by the Regional Ethical Review Board, Karolinska Institutet, Stockholm (Reg. No. 2011/1589-31/5).

ii The process of delegating the work to the home is the focus of my next research project, financed by the Swedish Research Council (2013-2015). At the moment six young patients are keeping video diaries at home, starting on the very day they get the braces.

iii If someone is dissatisfied with the orthodontist's decision they may ask for a second opinion at the clinic. If the patient appeals against the decision, the case is treated by the dental care board, a panel consisting of an orthodontist and laypersons who supervise and apportion the resources for orthodontics.
} 